\title{
Portable Electronic Nose for Discrimination of Indonesian Robusta Coffee Aroma with Varied Roasting Temperature Correlated with Gas Chromatography Mass Spectrometry
}

\author{
Yesiana Arimurti ${ }^{1 *}$, Kuwat Triyana ${ }^{2}$, and Sri Anggrahini ${ }^{3}$ \\ ${ }^{1}$ Department of Physics Education, Universitas Sebelas Maret \\ ${ }^{2}$ Department of Physics, Universitas Gadjah Mada \\ ${ }^{3}$ Departement of Food Science and Technology, Universitas Gadjah Mada \\ *yesiana.arimurti@staff.uns.ac.id
}

\begin{abstract}
The quality of coffee is strongly affected by its aroma, so that instrument for aroma testing is necessary especially for quality control. In this research, coffee aroma was tested using electronic nose and then correlated to gas chromatography-mass spectrometry (GC-MS). The green beans of robusta coffee (coffee canephora var.robusta) originated from Sumatra was used as a testing sample. The roasting temperature was varied to be $180{ }^{\circ} \mathrm{C}, 195{ }^{\circ} \mathrm{C}$, and $210{ }^{\circ} \mathrm{C}$, while the roasting time was set to be constant at 20 minutes. After the roasting process, the coffee beans were grounded using a coffee grinder. The feature of the response signal for each gas sensors of the electronic nose to ground coffee aroma, was extracted using two methods; i.e. gradient multiplied by signal peak and average value. The principle component analysis (PCA) was applied to discriminate the aroma of ground coffee with varied roasting temperature. The scoreplot of PCA analysis shows a clear discrimination of each coffee aroma, produced by different roasting temperature. From the GCMS analysis, it is clearly confirmed that more aromatic compounds detected when the roasting temperature increase. It is correlated with the discrimination result using electronic nose. The loading plot interpretation provides information that TGS822 and TGS826 are the most affecting sensors for discrimination of coffee aroma with varied roasting temperature. In the future, the electronic nose is potentially applied in coffee industry for quality control during process.
\end{abstract}

Keywords: electronic nose, robusta coffee, aroma, roasting temperature, GC-MS

\section{INTRODUCTION}

Aroma and taste of coffee developed during roasting process that depends on temperature and time. Coffee beans undergo a chain of reactions that lead to a change of chemical composition. Variation of roasting temperature and time will produce particular aroma profile with certain degree of roasting. Light roasted coffee gives an original taste of coffee bean that is affected by soil condition and weather. The darker degree of roasting, the original taste of coffee covered by the taste and aroma developed during roasting process, so that the sulphuruous/roasty, earthy, and smoky note become more intense ${ }^{[1]}$.

In the coffee industry, availability of quality control technique is very important ${ }^{[2]}$. Aroma testing is a part of quality control process that play an important role in fixing price, decreasing loss, and industry sustainability. Therefore, quality control technique of coffee product is one of crucial thing and research in this field still developing. 
Electronic nose (e-nose) technology and its application still developing in many fields including food technology. Some of those applications are : testing of compositions and properties of palm civet coffee (Kopi Luwak) and Ethiopian civet coffee ${ }^{[3]}$, discrimination of green tea quality, prediction of sensory quality change of meat product (pizza topping) during storage ${ }^{[4]}$, classification of Pecorino cheese based on ripening time and production technique ${ }^{[5]}$, sensory and microbiological quality assessment of beef fillets ${ }^{[6]}$, evaluation of Chinese tea correlated with sensory properties and classification according to grade level ${ }^{[7]}$, study of peach freshness ${ }^{[8]}$, and chemometric discrimination of Philippine civet coffee ${ }^{[9]}$. Electronic nose become one of alternative solution for a aroma testing instrumentation that is easy to use, multi purpose, and relatively low cost.

This research focus on discrimination of robusta coffee (coffea canephora var.robusta) aroma with varied roasting temperature using e-nose. Two feature extraction methods are applied to e-nose signal response in order to obtain best variance in PCA. The discrimination result is correlated to GCMS analysis, so that the rapid and accurate instrumentation for aroma testing can be obtained.

\section{MATERIAL AND METHOD}

\section{Material}

One kilogram of first grade robusta coffee beans (coffea canephora var.robusta) were obtained from Sumatra, Indonesia. These coffee beans were processed with wet method. Only coffee beans with large size, $7 \mathrm{~mm}$ up, were selected.

\section{Preparation}

All green coffee beans were roasted with rotary roaster in Process Engineering Laboratory, Faculty of Agriculture Technology, Universitas Gadjah Mada. The beans are roasted for 20 minutes in three temperature variation, $180{ }^{\circ} \mathrm{C}, 195{ }^{\circ} \mathrm{C}$, and $210{ }^{\circ} \mathrm{C}$. After roasting and cooling process, the coffee beans were grinded into powder.

\section{Electronic Nose (e-nose)}

The analysis of coffee aroma were performed using electronic nose (e-nose) that is developed in Material Physics and Instrumentation Laboratory, Universitas Gadjah Mada. This e-nose consist of sample chamber, a detector unit containing an array of eigth metal oxide gas sensors, temperature sensor, heater, fan, and data acquisition system connected directly to the computer.

Firstly, e-nose was switched on and heated for about 30 mins or until stable heater temperature was reached, about $50.0 \pm 0.5^{\circ} \mathrm{C}$ to find the baseline. Then, data recording was conducted when sensors only affected by the air. Output response signal for free air was used as baseline.

Repeat testing conducted for four signal peak, each sample. The sampling and flushing fans rotated with the same speed and time. One minute sampling and one minute flushing. Fiveteen minutes rest time were taken before testing the next sample. 


\section{Feature Extraction}

Chemometric analysis was done using Principal Component Analysis with firstly applied preprocessing to the response signal in order to obtain the best discrimination. Two feature extraction methods were selected as preprocessing method, they are:

- Gradient multiplied with signal peak. Using gradient equation $m=\frac{\Delta y}{\Delta x}$

- $\quad$ Average value. Using equation $A V_{M}=\frac{a_{M, 1}+a_{M, 2}+\cdots+a_{M, 12}}{12},(M=1,2, \ldots ., 8)$, with $\mathrm{M}$ is the M-th sensor anda $A V_{M}$ is average value of sensor's response in 60 second $^{[10]}$

Multivariate statistical analysis was used to establish a correlation between sensors and the characterictics of aroma. Principal component analysis (PCA) could reduce the dimensionality of numerical data setting in multivariate statistical analysis. The main features of PCA are score plot and loads plot. Score plot is coordination of data in a new base and generally used for studying the character location of coffee aroma. The contribution to each element of sensors is described by load plot. Loads plot also can used to generate information on the contribution of sensors to each principle component ${ }^{[11]}$.

\section{Correlation between e-nose and GCMS}

GCMS analysis was conducted using GCMS-QP2010S SHIMADZU, with AGILENT HP 5 MS column. Column length is 30 meter, and Helium is used as carrier gas. The result analysis was correlated to chemometric analysis, so that identification of coffee aroma pattern can be obtained.

\section{RESULT AND DISCUSSION}

\section{Chemometric analysis using PCA}

\section{a. Gradient multiplied with signal peak.}

Response signals of electronic nose for roasting tempertaure $180^{\circ} \mathrm{C}, 195^{\circ} \mathrm{C}$ and $210^{\circ} \mathrm{C}$ are shown by Figure 1a, 1b, and 1c, respectively. Preprocessing method was applied to response signal using two kind of feature extraction: gradient multiplied with signal peak and average value. Gradient was taken by draw best line through data sets when signal ascending or when e-nose start sniffing out the coffee sample aroma, until reach the maximum linearity. For all sample, 5 data points were still considered as linear, so that the gradient value can be taken. 

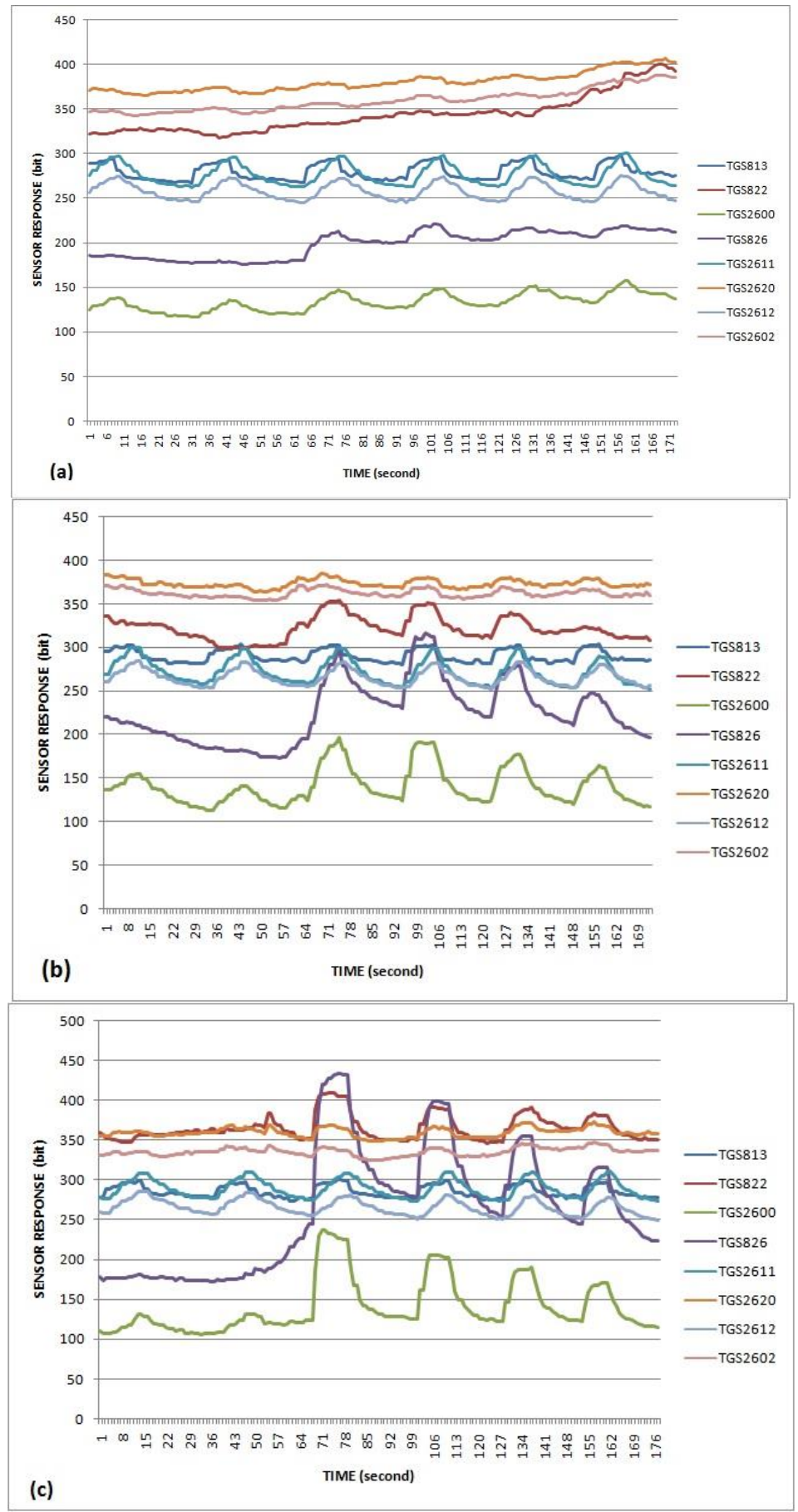

Figure 1. Response signal for each roasting temperature (a) $180{ }^{\circ} \mathrm{C}$, (b) $195{ }^{\circ} \mathrm{C}$, and (c) $210{ }^{\circ} \mathrm{C}$

PCA scoreplot for discrimination of coffee aroma roasted in $180{ }^{\circ} \mathrm{C}, 195{ }^{\circ} \mathrm{C}$, and $210{ }^{\circ} \mathrm{C}$ is shown in Figure 2a and PCA scoreplot for discrimination of coffee aroma roasted in 180 ${ }^{\circ} \mathrm{C}$ and $210{ }^{\circ} \mathrm{C}$ is shown in Figure $2 \mathrm{~b}$. For those two scoreplot, can be observed that there are aroma classification based on roasting temperature, though there is data point that located out of its group. 

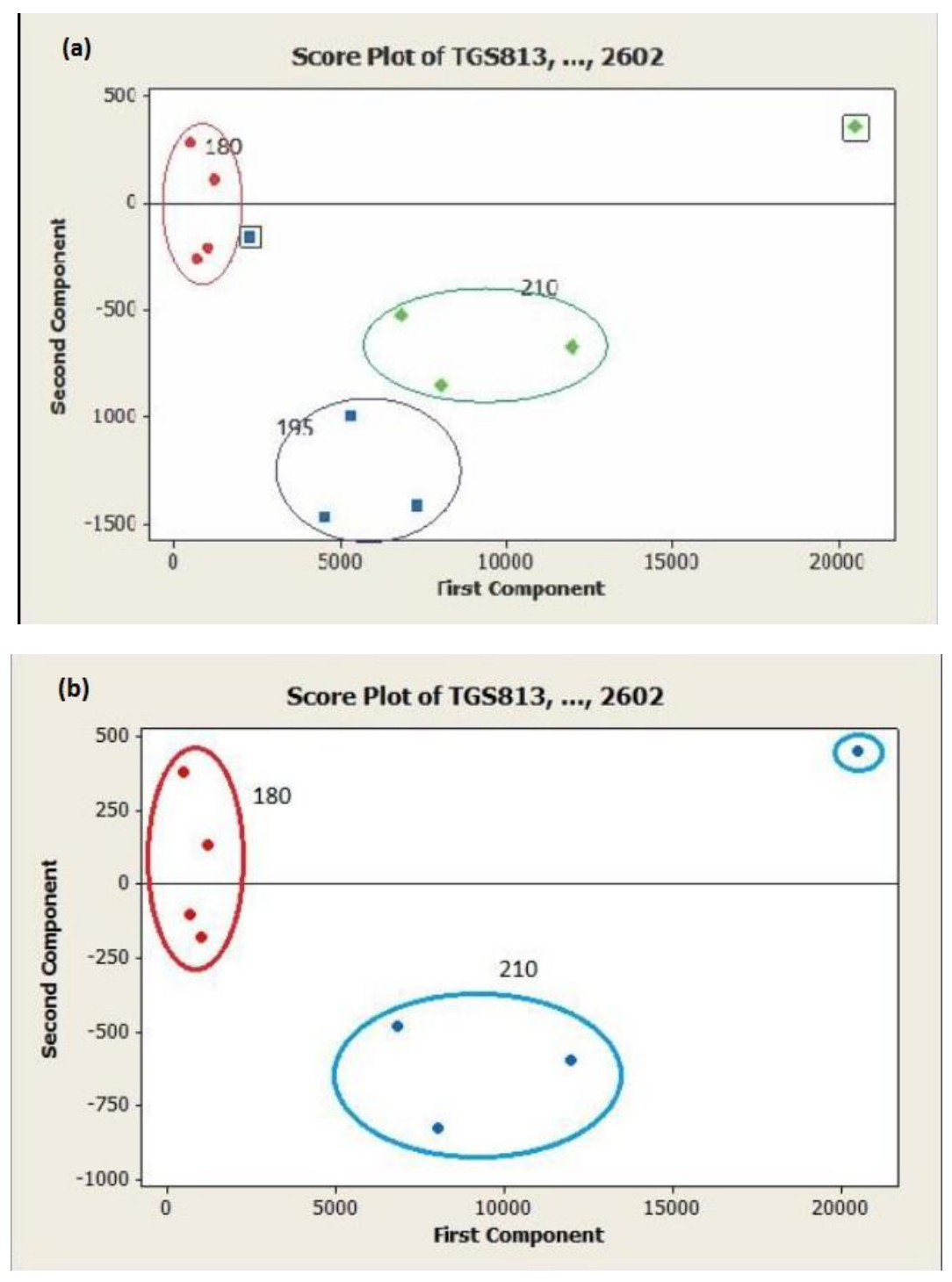

Figure 2. (a) PCA scoreplot for discrimination of Sumatra coffee aroma roasted in $180{ }^{\circ} \mathrm{C}, 195{ }^{\circ} \mathrm{C}$, and 210 ${ }^{\circ} \mathrm{C}$ and (b) PCA scoreplot for discrimination of coffee aroma roasted in $180{ }^{\circ} \mathrm{C}$ and $210{ }^{\circ} \mathrm{C}$ using gradient feature extraction

\section{b. Average Value}

Figure $3 \mathrm{a}$ and $3 \mathrm{~b}$ shows the PCA plot of Sumatra robusta coffee aroma discrimination with three variation of roasting temperature $\left(180{ }^{\circ} \mathrm{C}, 195{ }^{\circ} \mathrm{C}\right.$, dan $\left.210{ }^{\circ} \mathrm{C}\right)$ and two roasting temperature variation $\left(180{ }^{\circ} \mathrm{C}\right.$ dan $\left.210{ }^{\circ} \mathrm{C}\right)$. Based on Picture 2 , it can be clearly observed that there are two group aroma. It means that e-nose can discriminate the coffee aroma with varies roasting temperature. Compared to the score plot shown by Figure $2 \mathrm{a}$ and $2 \mathrm{~b}$, scoreplot that applied the average value feature extraction shows better discrimination result. 

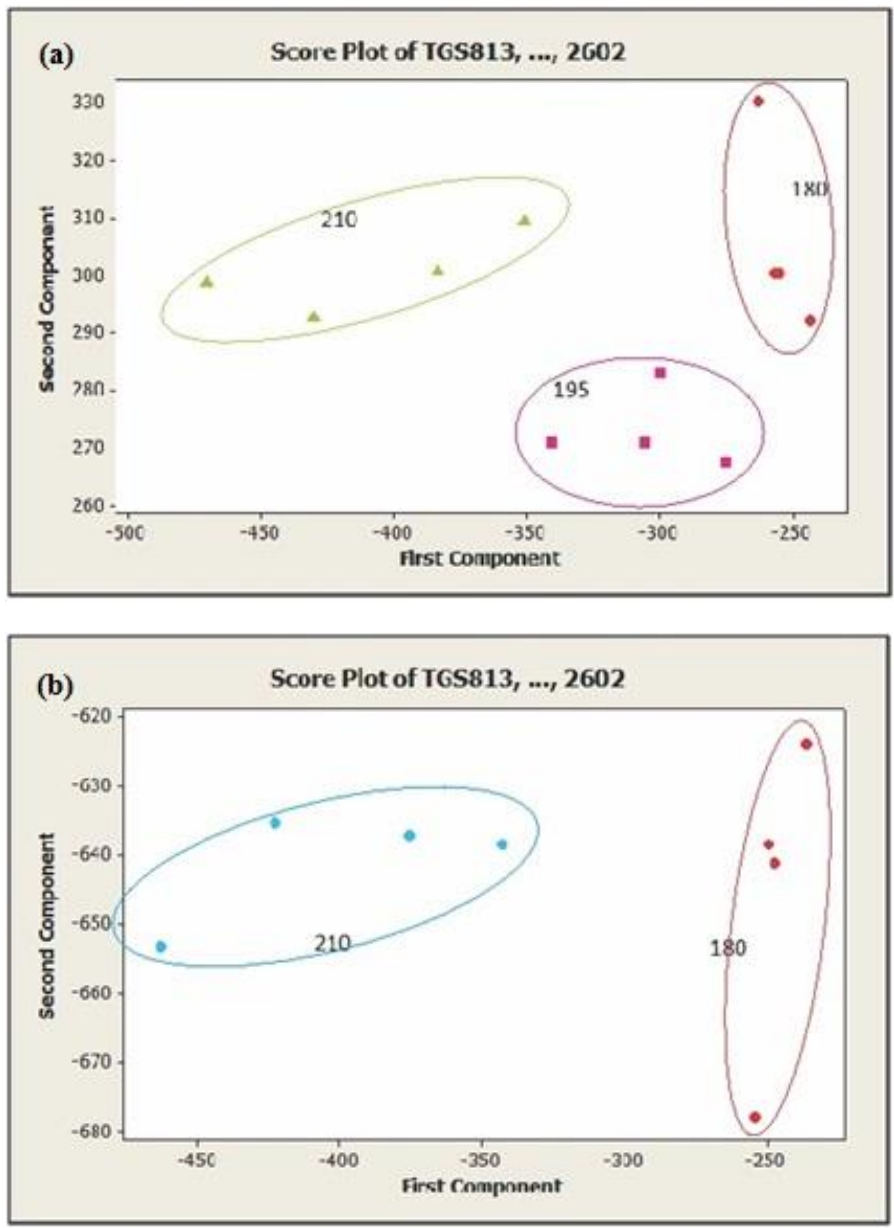

Figure 3. (a) PCA scoreplot for discrimination of Sumatra coffee aroma roasted in $180{ }^{\circ} \mathrm{C}, 195{ }^{\circ} \mathrm{C}$, and 210 ${ }^{\circ} \mathrm{C}$ and (b) PCA scoreplot for discrimination of coffee aroma roasted in $180{ }^{\circ} \mathrm{C}$ and $210{ }^{\circ} \mathrm{C}$, using average value feature extraction

\section{c. Correlation between electronic nose and GC-MS}

The GC-MS spectrum for robusta coffee from Sumatra roasted in temperature $180{ }^{\circ} \mathrm{C}, 195$ ${ }^{\circ} \mathrm{C}$, and $210{ }^{\circ} \mathrm{C}$ is respectively shown by Figure 4, 5, and 6. Table 1, 2, and 3 show the list of all compounds detected by GC-MS in the coffee samples. The volatile compounds in coffee contain of some groups; i.e. hydrocarbon, alcohol, aldehyde, ketone, carboxylic acid, esther, pyrazin, pyrol, pyridine, sulphuric compounds, furan, phenol, and oxazoles ${ }^{[1]}$. Not all of volatile compounds determine the aroma of coffee. In Table 1, 2, and 3, the aromatic compounds are marked with the star sign $(*)$. In the coffee sample roasted in temperature $180{ }^{\circ} \mathrm{C}$ and $195{ }^{\circ} \mathrm{C}$, butyraldehyde compound was detected, and the number of this compound increase as well as the roasting temperature increasing. It is shown by the percentage of area of butyraldehyde compound peak, that is $0.27 \%$ in $180{ }^{\circ} \mathrm{C}$ roasted coffee and $0.93 \%$ in $195{ }^{\circ} \mathrm{C}$ roasted coffee. While in $210{ }^{\circ} \mathrm{C}$ roasted coffee, there is fufuryl alcohol compound which has percentage of area as $1.03 \%$. It is one of aromatic compounds in coffee that give special aroma profile. Furfuryl alcohol give a 'burnt' aroma description of the coffee beans ${ }^{[12]}$. Beside furfuryl alcohol, also detected some aromatic compounds from the esthers group; i.e. hexanoic acid-butyl ester, tridecanoic acid-methyl ester, hexadecanoic acid-ethyl ester, hexadecanoic acid-methyl ester, nonadecanoic acid-ethyl ester, elaidic acid-methyl ester, octanoic acid-furfuryl alcohol ester, hexadecatrinoic acid-methyl ester. It is also detected the aromatic compounds from 
phenols group; i.e. 2,6-dimethoxy-4-allyphenol, myristcin, also from furans groups; i.e. 7(2,4-dinitrophenoxy)-2,3-dihydro-2,2-dimethyl- benzofuran.

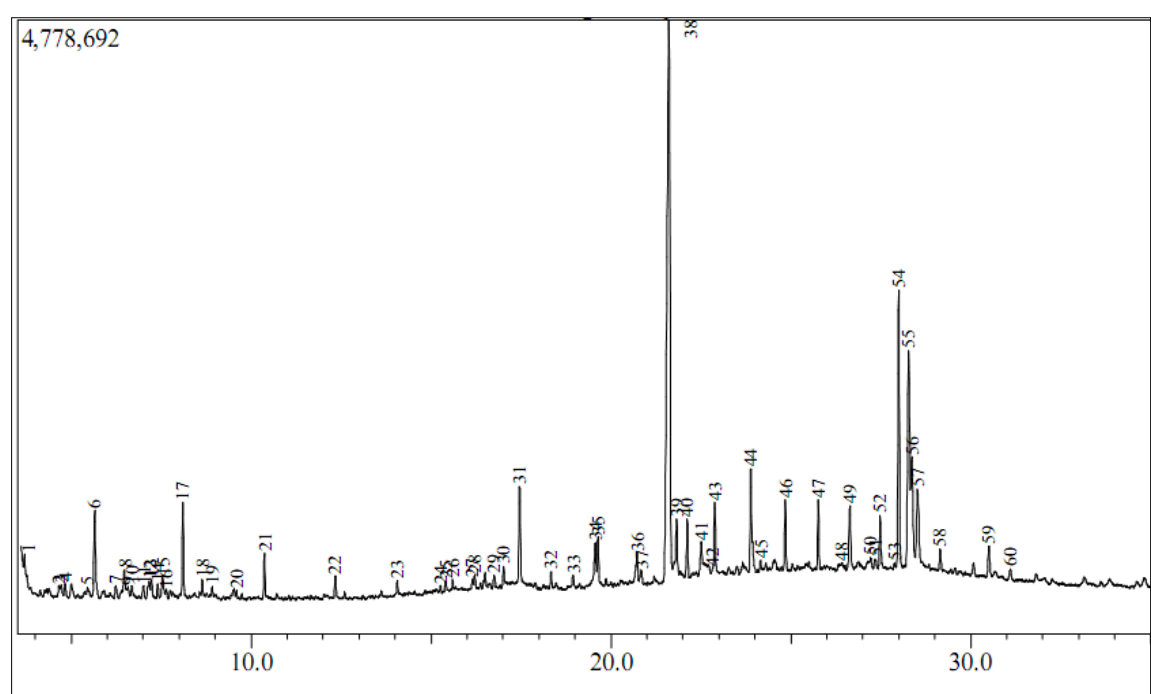

Figure 4. Spectrum of GCMS for sample of robusta coffee from Sumatra roasted in $180 \pm 4{ }^{\circ} \mathrm{C}$ for 20 minutes

Table 1. List of compounds detected by GCMS for robusta coffee sample from Sumatra roasted in $180 \pm 4$ ${ }^{\circ} \mathrm{C}$ for 20 minutes

\begin{tabular}{|c|c|c|c|}
\hline Peak & Compounds & Peak & Compounds \\
\hline 1 & Octane & 31 & Myristcin* \\
\hline 2 & 1,2,4-trimethylcyclohexane & 32 & heptadecane \\
\hline 3 & isobutyraldehyde diethyl acetal* & 33 & 2,6,10-trimethyl- pentadecane \\
\hline 4 & 2-methyloctane & 34 & hexadecane \\
\hline 5 & cis-1-ethyl-4-methylcyclohexane & 35 & 2,6,11-trimethyldodecane \\
\hline 6 & Nonane & 36 & isohexadecane \\
\hline 7 & Octylacetylene & 37 & pentadecane \\
\hline 8 & n-octylacetylene & 38 & caffeine \\
\hline 9 & alpha.-pinene & 39 & Heptadecane \\
\hline 10 & 3-ethyl-2-methyl- Heptane & 40 & methyl hexadecanoate \\
\hline 11 & 5-methyl- Decane & 41 & n-hexadecoic acid \\
\hline 12 & 3,5-dimethyl- octane & 42 & Hexadecanoic acid, ethyl ester* \\
\hline 13 & 2-methylnonane & 43 & 1-butyl-2-pyrrolidinone \\
\hline 14 & 2,6-dimethyl- octane & 44 & 2,3,5,8-tetramethyl-decane \\
\hline 15 & Sabinene & 45 & octadecanoic acid, methyl ester* \\
\hline 16 & 2-.beta.-pinene & 46 & eicosane \\
\hline 17 & Decane & 47 & Eicosane \\
\hline 18 & 2,6-dimethylnonane & 48 & oelic acid amide \\
\hline 19 & isobutylcyclohexane & 49 & eicosane \\
\hline 20 & 2-methyl- decane & 50 & 1-cis-2-trans-4-cis-trivinyl- cyclohexane \\
\hline 21 & Undecane & 51 & cyclopropaneoctanoic acid \\
\hline 22 & Dodecane & 52 & pentatriacontane \\
\hline 23 & Tridecane & 53 & androst-4,16-diene-3-one \\
\hline 24 & 3-methyl-5-propyl- nonane & 54 & di-n-octyl phthalate \\
\hline 25 & 2-n-butyl-8-n-hexyldecahydronaphthalene & 55 & valencene \\
\hline 26 & Isododecane & 56 & androsta-4,16-dien-3-one \\
\hline 27 & muurolane-a & 57 & beta.-caryophyllene \\
\hline 28 & $\begin{array}{l}\text { octahydro- } 2,2,4,4,7,7 \text {-hexamethyl-, trans- } \\
\text { 1h-indene }\end{array}$ & 58 & eicosane \\
\hline 29 & $\begin{array}{l}\text { 1,3-dicyclopentyl-2-n- } \\
\text { dodecylcyclopentane }\end{array}$ & 59 & spinacene \\
\hline 30 & isohexadecane & 60 & nor-hexatriacontane \\
\hline
\end{tabular}




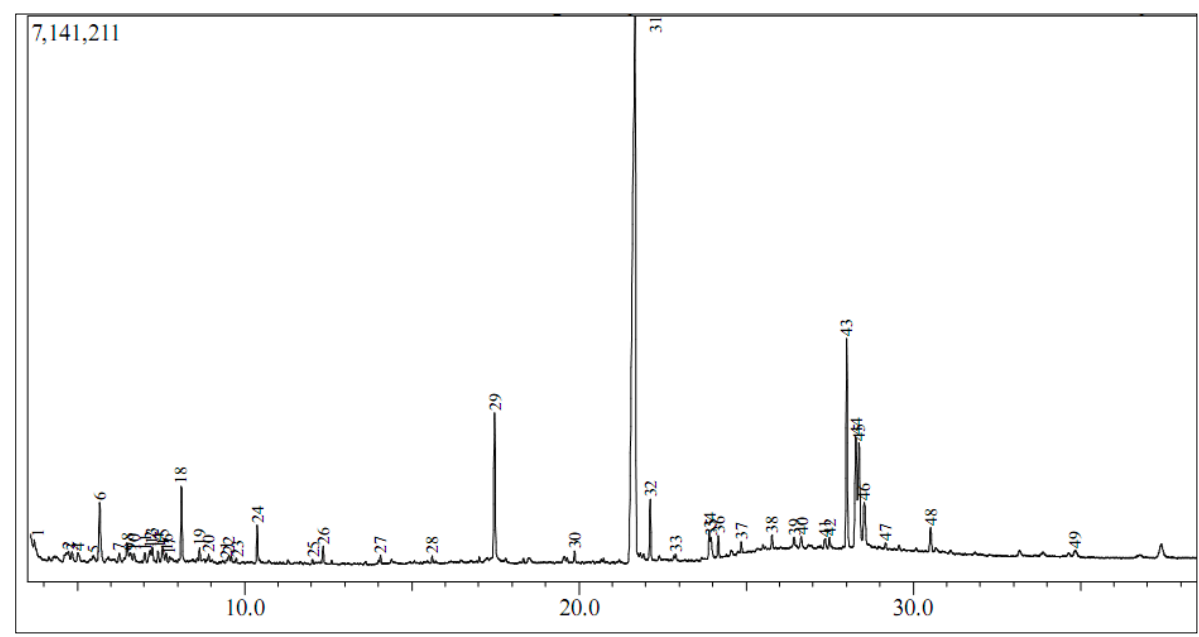

Figure 5. Spectrum of GCMS for sample of robusta coffee from Sumatra roasted in $195 \pm 2{ }^{\circ} \mathrm{C}$ for 20 minutes

Table 2. List of compounds detected by GCMS for robusta coffee sample from Sumatra roasted in $195 \pm 2$ ${ }^{\circ} \mathrm{C}$ for 20 minutes

\begin{tabular}{|c|c|c|c|}
\hline Peak & Compounds & Peak & Compounds \\
\hline 1 & isooctane & 26 & isododecane \\
\hline 2 & butyraldehyde diethyl acetal* & 27 & tridecane \\
\hline 3 & 2,4-dimethylheptane & 28 & 1-chloro- tetradecane \\
\hline 4 & 2,5-dimethylheptane & 29 & Myristcin* \\
\hline 5 & dimethyl-3,5 heptene-3 & 30 & methyl hexadecanoate \\
\hline 6 & n-nonane & 31 & caffeine \\
\hline 7 & n-octylacetylene & 32 & hexadecanoic acid, methyl ester* \\
\hline 8 & 2-propyl-4-methyl-pentanol-1 & 33 & eicosane \\
\hline 9 & .alpha.-pinene & 34 & octahydro-1-(2-octyldecyl)- pentalene \\
\hline 10 & 3-ethyl-2-methyl- heptane & 35 & 16-octadecenoic acid, methyl ester* \\
\hline 11 & isodecane & 36 & methyl 16-methylheptadecanoate \\
\hline 12 & 3,5-dimethyloctane & 37 & n-heptadecane \\
\hline 13 & 2-methylnonane & 38 & pentacosane \\
\hline 14 & 2,6-dimethyloctane & 39 & oleic acid amide \\
\hline 15 & sabinene & 40 & octadecane \\
\hline 16 & 2-.beta.-pinene & 41 & Linoleoyl chloride \\
\hline 17 & $\begin{array}{l}\text { 1,2-dimethyl-3-(1-methylethyl)- } \\
\text { cyclopentane }\end{array}$ & 42 & n-tricosane \\
\hline 18 & decane & 43 & di-n-octyl phthalate \\
\hline 19 & 2,6-dimethylnonane & 44 & valencene \\
\hline 20 & 2-cyclohexyl-octane & 45 & androst-4,16-diene-3-one \\
\hline 21 & 5-methyldecane & 46 & androst-4,16-diene-3-one \\
\hline 22 & trans-.alpha.-Ionone & 47 & triacontane \\
\hline 23 & 3-methyl- decane & 48 & spinacene \\
\hline 24 & undecane & 49 & beta.-dihydro- fucosterol \\
\hline 25 & terpineol-4 & & \\
\hline
\end{tabular}




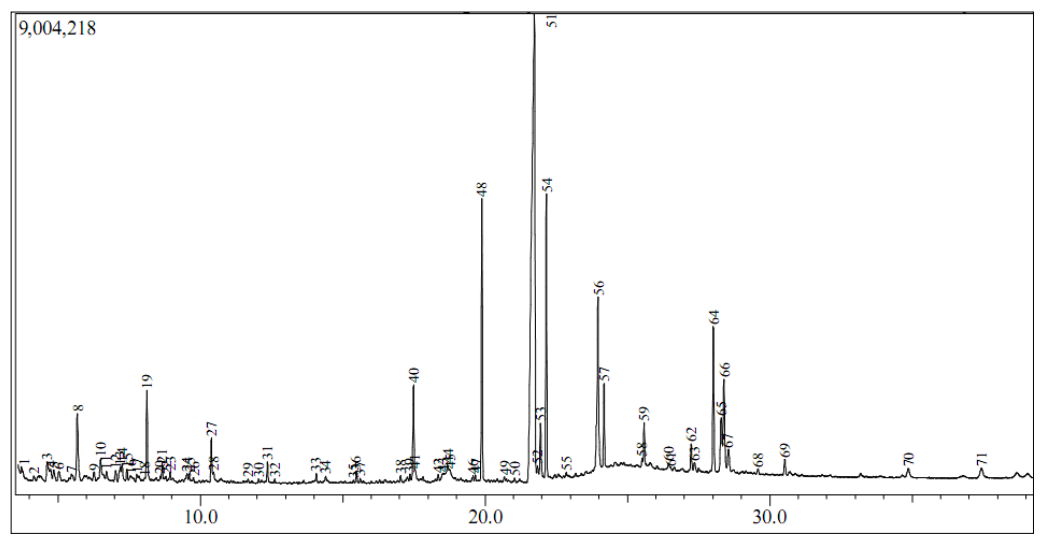

Figure 6. Spectrum of GCMS for sample of robusta coffee from Sumatra roasted in $210 \pm 2{ }^{\circ} \mathrm{C}$ for 20 minutes

Table 3. List of compounds detected by GCMS for robusta coffee sample from Sumatra roasted in $210 \pm 2$ ${ }^{\circ} \mathrm{C}$ for 20 minutes

\begin{tabular}{|c|c|c|c|}
\hline Peak & Compounds & Peak & Compunds \\
\hline 1 & Octane & 35 & geranyl acetate \\
\hline 2 & 2,6-dimethyl-heptane & 36 & Copaene \\
\hline 3 & furfuryl alcohol* & 37 & Tridecane \\
\hline 4 & 1,1-diethoxy-2-methyl-propane & 38 & Isododecane \\
\hline 5 & Isooctane & 39 & methyl dodecanoate \\
\hline 6 & 2,5-Dimethylheptane & 40 & Myristcin* \\
\hline 7 & cis-1-ethyl-4-methylcyclohexane & 41 & delta.-cadinene \\
\hline 8 & Nonane & 42 & Isohexadecane \\
\hline 9 & octylacetylene & 43 & 2,6-dimethoxy-4-allylphenol* \\
\hline 10 & 2,4-dimethyl-1-decene & 44 & 2,3,4-trimethyl-3-pentanol \\
\hline 11 & 3-ethyl-2-methylheptane & 45 & hexanoic acid, butyl ester* \\
\hline 12 & isooctylvinyl ether & 46 & Dodecane \\
\hline 13 & 3,5-dimethyloctane & 47 & 2,6,11-trimethyldodecane \\
\hline 14 & 2-Methylnonane & 48 & tridecanoic acid, methyl ester* \\
\hline 15 & 3-methylnonane & 49 & hexadecanoic acid, ethyl ester* \\
\hline 16 & $\begin{array}{l}\text { 2-methyl-4-(2-methylpropyl)- } \\
\text { cyclopentanone }\end{array}$ & 50 & hexadecanoic acid, methyl ester* \\
\hline 17 & 1-methyl-3-propyl-cyclohexane & 51 & Caffeine \\
\hline 18 & 1,2,4-trimethylbenzene & 52 & cis-8,11,14-eicosatrienoic acid \\
\hline 19 & Decane & 53 & methyl palmitoleinate \\
\hline 20 & 2,2,3-trimethyl-1-vinyl-3-cyclopentene & 54 & hexadecanoic acid, methyl ester* \\
\hline 21 & 2,6-dimethylnonane & 55 & nonadecanoic acid, ethyl ester* \\
\hline 22 & isohexadecane & 56 & elaidic acid methyl ester* \\
\hline 23 & 2-cyclohexyloctane & 57 & methyl 16-methylheptadecanoate \\
\hline 24 & linalyl alcohol & 58 & methyl arachidonate \\
\hline 25 & 2-methyl- decane & 59 & $\begin{array}{l}\text { 6e-methyl-1-methylen-2e,4e-divinyl- } \\
\text { cyclohexane }\end{array}$ \\
\hline 26 & 3-methyldecane & 60 & oleic acid amide \\
\hline 27 & Undecane & 61 & octanoic acid, furfuryl alcohol ester* \\
\hline 28 & Furaldehyde* & 62 & $\begin{array}{l}\text { 1,5-diethenyl-3-methyl-2-methylene-, } \\
\text { (1.alpha.,3.alpha.,5.alpha.)- cyclohexane }\end{array}$ \\
\hline 29 & 2,9-dimethyldecane & 63 & hexadecatrienoic acid, methyl ester* \\
\hline 30 & terpineol-4 & 64 & di-n-octyl phthalate \\
\hline 31 & isododecane & 68 & $\begin{array}{l}\text { 7-(2,4-dinitrophenoxy)-2,3-dihydro-2,2- } \\
\text { dimethyl- benzofuran* }\end{array}$ \\
\hline 32 & decane, 2,6,7-trimethyl- decane & 69 & Spinacene \\
\hline 33 & isododecane & 70 & Cordulan \\
\hline 34 & 3'-methoxyacetophenone & 71 & Stigmasterol \\
\hline
\end{tabular}


Table 1 and 2 shows that the aromatic compounds detected by GC-MS for coffee roasted in $180{ }^{\circ} \mathrm{C}$ and $195^{\circ} \mathrm{C}$ are not as many as detected aromatic compounds of coffee roasted in $210{ }^{\circ} \mathrm{C}$ (shown in Table 3). Based on this analysis, it can be concluded that the higher roasting temperature, the more aromatic compounds can be detected. It support the analysis result of electronic nose that shows the clear clusters separation of coffee aroma roasted in $180{ }^{\circ} \mathrm{C}$ and $210{ }^{\circ} \mathrm{C}$. In this research, some of coffee aromatic compounds were not detected by GC-MS, such as pyrazine, pyridine, pyrole, mercaptan, and so on. It might be due to inappropriate method of coffee sample extraction before the sample injected into GC-MS column. Beside that, the error of temperature setting of coffee bean roaster might contribute to the coffee aromatic compounds that can't be detected. So that the actual roasting temperature could be inappropriate with what shown in the temperature indicator. The coffee bean roaster need to be calibrated annually, in order to obtain an accurate roasting temperature.

\section{d. Loading Plot Interpretation}

Loading plot identify the most affecting variable to the first component and second component. In this research, the variables describe the sensors used in electronic nose, symbolized with $\mathrm{C} 1, \mathrm{C} 2, \mathrm{C} 3, \mathrm{C} 4, \mathrm{C} 5, \mathrm{C} 6, \mathrm{C} 7$, and C8 that represent the gas sensors TGS 812, TGS 822, TGS 2600, TGS 826, TGS 2611, TGS 2620, TGS 2612, and TGS 2602, respectively. The value of loading varies from -1 to 1 . Loading close to 1 and -1 represent the most dominant influencing variables. And loading close to 0 indicate that the variables has less influence to the component. Loading plot of electronic nose response signal for coffee aroma discrimination with varied roasting temperature is shown by Figure 7 and Figure 8 .

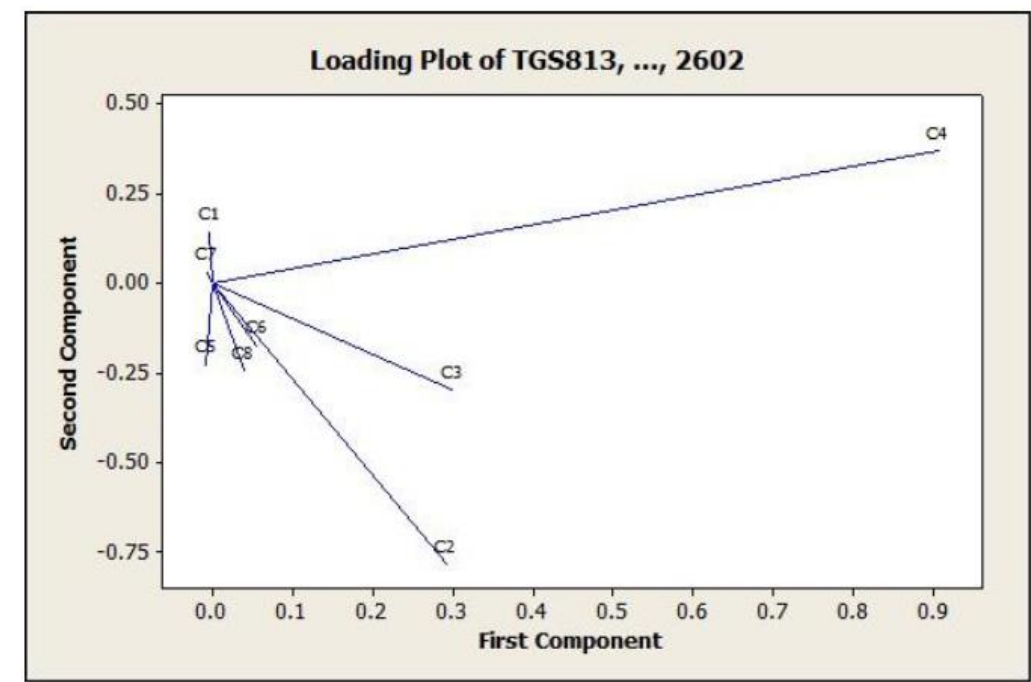

Figure 7. Loading plot of electronic nose response signal for coffee aroma discrimination with varied roasting temperature using gradient feature extraction 


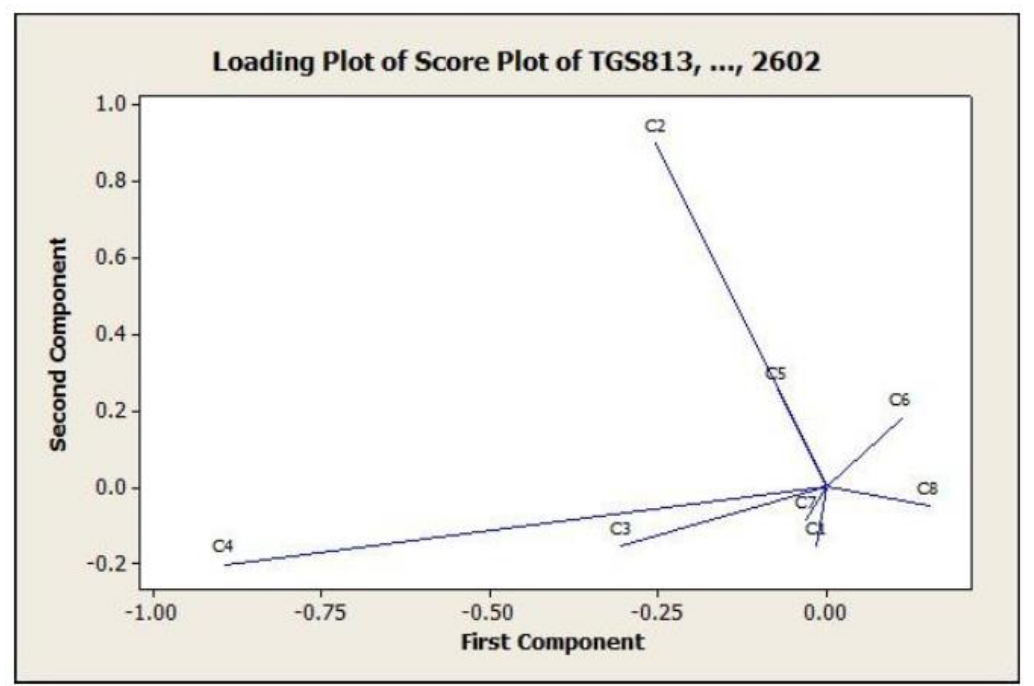

Figure 8. Loading plot of electronic nose response signal for coffee aroma discrimination with varied roasting temperature using average value feature extraction

Based on Figure 7 and Figure 8, variables which have loading value close to 1 and -1 for first or second component are C2 and C4 or TGS 822 and TGS 826, respectively. Gas sensor TGS 822 is a tin dioxide $\left(\mathrm{SnO}_{2}\right)$ semiconductor based sensor that has high sensitivity to the presence of vapors of organic solvent and some combustible gases such as carbon monoxide. It is can be accepted if this sensor give better response signal to the coffee aroma discrimination, since the coffee beans undergo the roasting proccess that produce an organic vapors and 'burnt' characteristic aroma. It is also confirmed by the GCMS analysis, which detect the furfuryl alcohol as a contributor to the 'burnt' aroma description. Gas sensor TGS 826 is a metal oxide semiconductor based sensor which has high sensitivity to the presence of ammonia. It is usually applicated to detect ammonia in the agricultural field.

\section{CONCLUTION}

The increasing of roasting temperature cause more aromatic compounds exist in coffee sample and detected by GC-MS. The PCA scoreplot of electronic nose response signal shows that electronic nose can discriminate the aroma of robusta coffee with varied roasting temperature; $180{ }^{\circ} \mathrm{C}, 195{ }^{\circ} \mathrm{C}$, and $210{ }^{\circ} \mathrm{C}$. It is can be concluded by the scoreplot which shows clustering aroma profile between those three roasting temperature variation. The GC-MS analysis shows that there are a difference in the number of aromatic compounds detected for three variation of roasting temperature. It is correlated with the analysis of electronic nose response signal that show the difference coffee aroma pattern for each roasting temperature variation. The gas sensor TGS 822 and TGS 826 are the most affecting sensors for discrimination of coffee aroma with varied roasting temperature.

\section{ACKNOWLEDGEMENT}

We wish to thank to all laboratory officers of Food Processing Technology Lab., Universitas Gadjah Mada, for the guidance in using the coffee bean roaster. And also big thank to Prof. Dr. Sri Anggrahini for warm discussion about coffee and the result of GCMS analysis. 


\section{REFERENCES}

1 Clarke, R.J., \& Vitzthum, O.G. 2001. Coffee Recent Developments, Blackwell Science Ltd., Oxford

2 Pardo, M., Niederjaufner, G., Benussi, G., Comini, E., Faglia, G., Sberveglieri, G., Holmberg, M., \& Lundstrom, I. 2000. Data Processing Enhance The Classification Of Different Brands Of Espresso Coffee With An Electronic Nose, Sensor and Actuators $B, 69,397-403$

3 Cevoli, C., Cerretani, L., Gori, A., Caboni, M.F., Toschi, T.G., \& Fabbri, A. 2011. Classification of Pecorino Cheese Using Electronic Nose Combined with Artificial Neural Network and Comparison with GC-MS Analysis of Volatile Compounds, Food Chemistry, 129, 1315-1319

4 Vestergaard, J.S., Martens, M., \& Turkki, P. 2007. Application of an Electronic Nose System for Prediction of Sensory Quality Change of A Meat Product (Pizza Topping) During Storage, LWT, 40, 1095-1101

5 Marcone, M.F. 2004. Composition and Properties Of Indonesian Palm Civet Coffee (Kopi Luwak) and Ethiopian Civet Coffee, Food Research International ,37, 901-912

6 Guohua, H., Yuling, W., Dandan, Y., Wenwen, D., Linshan, Z., \& Lvye, W. 2012. Study of Peach Freshness Predictive Methods Based on Electronic Nose, Food Control, 28, 25-32

7 Papadopoulou, O.S., Panagou, E.Z., Mohareb, F.R., \& Nychas, G.E. 2013. Sensory and Microbiological Quality Assessment of Beef Fillets Using A Portable Electronic Nose In Tandem With Support Vector Machine Analysis, Food Research Internatinal, 50, 241-249

8 Qin, Z., Pang, X., Chen, D., Cheng, H., Hu, X., \& Wu, J. 2013. Evaluation of chinese tea by electronic nose and gas chromatography-mass spectrometry: corelation with sensory properties and classification according to grade level, Food Research International, 53, 864-874

9 Ongo, E., Falasconi, M., Sberveglieri, G., Anonelli, A., Montevecchi, G., Sberveglieri, V., Concina, I., \& Sevilla III, F. 2012. Chemometric Discrimination Of Philippine Civet Coffee Using Electronic Nose and Gas Chromatography Mass Spectrometry, Procedia Engineering, 47, 977-980

10 Yu, H., Wang, J., Zhang, H., Yu, Y., \& Yao, C. 2007. Identification of Green Tea Grade Using Electronic Nose Different Feature of Response Signal From E-Nose Sensors, Sensors and Actuators B, 128, 445-461

11 Liu, Ming, Xiaomin Han, Kang Tu, Leiqing Pan, Jian Tu, Lin Tang, Peng Liua, Ge Zhan, Qiding Zhong, \& Zhenghe Xiong. 2012. Application of Electronic Nose In Chinese Spirits Quality Control And Flavour Assessment, Food Control, 26, 564-570

12 Gonzales-Rios, O., Suarez-Quiroz, M.L., Boulanger, R., Barel, M., Guyot, B., Guiraud, J.P., \& Schorr-Galindo, S. 2007. Impact of "Ecological" Post-Harvest Processing on Coffee Aroma: II. Roasted Coffee, Journal of Food Composition and Analysis, 20, 297-307 